\title{
LA PENÍNSULA EN ROSARIO. \\ FRANCISCO ROCA Y LA CASA ESPAÑA \\ COMO MANIFESTACIÓN DE LAS VOLUNTADES ESTÉTICAS \\ DE LOS INMIGRANTES
}

\author{
Javier García Cano ${ }^{1}$
}

\begin{abstract}
"Cada edificio, cada casa que se construía traía un sueño aparejado, cada fachada que dibujaba parecía copiada de otra fachada europea original, italiana, catalana ofrancesa, pero muy a pesar de la idea del arquitecto o del artesano, para la forma adoptaron los nuevos diseños crearon un nuevo estilo, parecería que las ideas se llevaban y con el paso de las olas marinas se iban transformando, las ideas iban perdiéndose en la memoria y las formas se suavizaron $y$ adoptaron otro contenido..."

(Luis Gueilburt. Escultor. Barcelona)
\end{abstract}

\begin{abstract}
Resumen
La participación de los inmigrantes en la sociedad argentina definió gran parte del paisaje urbano de todas las ciudades del territorio. Asociado a cada grupo migratorio, los imaginarios y valores estéticos con origen en otros lugares, se convirtieron en definitorios de las diversas localías. Rosario es un caso paradigmático de esta forma de conformación de lugar, donde lo local es resultado de lo mundial y global. La conferencia tratará el caso del arquitecto mallorquín Francisco Roca i Simó que fuera responsable del proyecto y ejecución del edificio conocido como "Casa España".
\end{abstract}

Palabras clave: inmigración, manifestaciones estéticas, arquitectura.

\begin{abstract}
Immigrants' participation at the Argentinean society defined a big portion of urban landscape at every city in the territory. Imaginary and aesthetics values with origin at other places associated to every immigrants' group became a defining of diverse localities. Rosario is a paradigmatic case of this way of conformation of a place; where local is the result of world and global as well. This lecture will work with the case of Francisco Roca i Simo Majorcan architect who was responsible on design and building the "Spain House".

Keywords: immigration, esthetic manifestations, architecture.

\footnotetext{
${ }^{1}$ Programa Archivo de Imágenes Digitales. Instituto de Arte Americano e Investigaciones Estéticas jgcano@fibertel.com.ar
} "Mario J. Buschiazzo". Facultad de Arquitectura Diseño y Urbanismo - Universidad de Buenos Aires.
\end{abstract}




\section{La inmigración española en el país y la arquitectura de las vanguardias deci- monónicas}

El Modernismo como movimiento artístico se desarrolló a fines del siglo XIX y hasta los primeros años del siglo XX.

Las primeras referencias se producen en Inglaterra con los trabajos de John Ruskin (1819-1900), influenciado por el arte gótico, publicó una enorme cantidad de libros sobre literatura, pintura, arquitectura, escultura, estética y muchos otros temas sociales. Sus ideas se popularizaron e influyeron en el conocido movimiento Arts and Crafts (Artes y Oficios) que se caracteriza por un retorno a la naturaleza, a las formas graciosas, onduladas, delicadas, de un suave encanto, en las que son frecuentes vegetales, flores, insectos, peces, sirenas, dragones y pájaros de colores.

El Modernismo encontró su expresión en formas de arte bien distintas, en arquitectura por ejemplo, son frecuentes los exteriores en piedra, cerámica, profusión de hierro forjado, los interiores con paredes curvas y con una decoración exuberante.

La escultura, la pintura y las artes gráficas, dan un nuevo impulso a la selección de temas y su representación. Sin dudas, el lugar de las vanguardias europeas del siglo XIX estuvo asociado a la idea de la búsqueda de una nueva arquitectura. Tal como fuera en Francia y Bélgica el Art Nouveau, el Modernismo Catalán fue la expresión de este conglomerado de corrientes e ideas en el plano de la península ibérica. En todos los casos y regiones lo buscado fue "la nueva arquitectura". Una idea basada en las nuevas formas, las nuevas combinatorias de materiales, y una nueva manera de concebir el espacio, en particular los interiores.

La colectividad española fundó desde sus inicios, en la segunda mitad del siglo XIX, instituciones que sirvieron, entre otras cosas, para integrarse en el país, social, económica y políticamente. El nacimiento del mutualismo en la Provincia de Santa Fe, está estrechamente ligado a la rica evolución del pueblo santafesino y la ciudad de Rosario aparece como el centro más importante donde surgieron estas primeras entidades. Fue en esos momentos en que inmigrantes españoles crearon la Asociación Española de Socorros Mutuos (1857), y detrás de ellos los italianos con Unione y Benevolenza, el Centro Unión Dependientes, la Sociedad Cosmopolita, la Asociación Mutual Humberto Primo, la Sociedad de Socorros Mutuos Entre Orientales (hoy Casa Uruguaya), entre otras varias, con la particularidad que todas ellas, han llegado hasta nuestros días desafiando todas los vaivenes de la economía y las crisis más profundas que hemos padecido como país. Los pioneros del mutualismo, fueron sin duda las colectividades de inmigrantes, con su impronta particular y con el sello característico de construir un asociativismo mutualista que acompañó la historia de Rosario y que significaron casi el $40 \%$ de estas entidades en toda la Provincia de Santa Fe.

Y así fue que, a través de la arquitectura, estos inmigrantes, impusieron también "marcas" en la ciudad de la mano del Modernismo y de la denominada "Nueva Arquitectura".

A partir de 1880, Cataluña siente más sus diferencias con el resto de Europa. El Modernismo se traducirá en la expresión artística de ese sentir y testimonia- 
rá, a través de la adopción de las arquitecturas regionales, a la comunidad de inmigrantes españoles en Argentina, otorgando lo que podemos denominar "un perfil innovador y de vanguardia frente a las tradiciones académicas reinantes". El Modernismo en Cataluña tuvo una fantástica expansión, ya que el país estaba abierto a las corrientes procedentes de Europa, para afirmar sus elementos diferenciales con España y reforzar su nacionalismo, en un periodo liderado por la "Renaixença". Los Modernistas, creían en la imaginación creativa como productora de símbolos en contraste con los eclécticos que pensaban en el arte como representación objetiva de la realidad. De hecho, el Modernismo representó en todo el mundo y en especial en Cataluña la libertad para la creación de nuevas formas anteriormente no aceptadas, sacando al arte de sus limitaciones académicas.

El Modernismo catalán no solo refleja en su arquitectura la riqueza ornamental que es común a todo el Art Nouveau (Arte Nuevo), sino que manifiesta un interés por mantener y renovar las técnicas tradicionales de construcción y decoración, mezclando los materiales antiguos con los nuevos. Lo regional y lo local fueron las grandes características que identificaron a estas manifestaciones arquitectónicas y artísticas. En los primeros tiempos y en manos de los grandes ideólogos los logros estuvieron concentrados en Barcelona, sin embargo, y en la medida que otros artistas y arquitectos tomaron contacto con los autores catalanes, estas ideas comenzaron a tener presencia en muchos territorios.

Siendo que este proceso se desarrolla poco antes del gran proceso migratorio hacia tierras del nuevo mundo, la arquitectura de las vanguardias llegará incluso a América de manos de esos arquitectos, pero, debemos decir que en forma tardía. Cuando el Art Nouveau y el Modernismo Catalán ya no eran una novedad y en algunos casos ya estaban siendo olvidados en sus territorios de origen, comenzaban a llegar al otro lado del océano, incluyendo nuestro país. El modernismo, una vez emigrado fuera de Cataluña, pasó a ser uno de los estilos que identificó a los españoles fuera de la península. En Argentina, no fue mayoritario, pero formó parte de la lista de opciones que se utilizaron para dar cuenta de cierta expresión representativa de la hispanidad.

"Los comitentes de las obras modernistas en el país eran inmigrantes españoles devenidos en burguesía enriquecida, que aceptaron al modernismo como <modernidad>, como ostentación y autonomía, como sentido de diferenciación individualista” (R. Gutiérrez. 2010:125).

En este marco, es que Francisco Roca i Simó aparecerá en nuestro escenario. De por sí, él ya había participado en el proceso de migración de ésta arquitectura fuera de Cataluña llevándola a las islas Baleares.

\section{Hombre, ideas y obra}

Nacido en Lérida, Palma de Mallorca en 1874, estudia en la Escuela de Arquitectura de Madrid y en 1907 se instala en Palma nuevamente donde comienza 
a desarrollar su trabajo. Su formación no marcó la referencia hacia el Modernismo Catalán, sin embargo hay que recordar que el fenómeno de la búsqueda de la "Nueva Arquitectura" no se circunscribe a Cataluña en lo que a España implica. En todas las grandes ciudades de la Península, hubo experiencias que indagaron en algún tipo de modernidad y novedad. El intento de alejarse del código clásico en un sentido estricto fue parte de los proyectos arquitectónicos de algunos autores, aún sin ser parte del más famoso de todos ellos (el Modernismo Catalán). Madrid fue también una plaza en España donde hubo búsquedas de modernidad decimonónica. De esa época son la casa Cañelas, la casa Roca y la casa Segura, consideradas sus primeras obras modernistas con predominio de líneas rectas y con una decoración claramente secesionista (haciendo alusión a las coincidencias formales con obras pertenecientes al movimiento conocido como "Secesión Vienesa"). Con los proyectos de la casa de Jaume Quetglas (1908) pero sobretodo con la Casa Casasayas (1908/10) y la pensión Menorquina (1909/11), ambas conforman un complejo proyectual en dos esquinas que se inician con un año de diferencia entre si, es donde se nota una fuerte influencia de Antoni Gaudí, especialmente del estilo de las casas Batlló y/o Milá.

Hacia finales de 1909 se traslada a la Argentina donde permanecerá hasta 1915. Algunos autores consideran que se encuentra en este país hasta 1919, aunque pensamos que pudo haber ido y venido por el desarrollo que presentan algunas obras tanto aquí como en la península. Pero la fecha de 1919 lo coloca definitivamente de vuelta en España. Por su traslado a la Argentina deberá dejar la continuidad del proyecto de Can Casasayas y la Pensión Menorquina en manos de Guillem Reynes. Esta obra será considerada como una de las muestras más representativas del modernismo mallorquín, siendo declarada en el 2001 Monumento Histórico y Artístico de Palma de Mallorca.

De vuelta en su país adopta un lenguaje más historicista representado en el Colegio Notarial de Palma y en el hotel Mediterráneo. Luego de finalizada la Primera Guerra se radica en Madrid y su obra se va a orientar hacia una arquitectura más triunfalista, siendo un ejemplo el Monumento al Crucero Baleares. Fallece en Madrid en el año de 1940 luego de una larga dolencia.

Una vez en la Argentina se radica en la ciudad de Rosario. Casado con una de las hijas de Juan Cabanellas (influyente comerciante de la colectividad catalana en Rosario), esto le facilitó su relación con los inmigrantes españoles radicados en la ciudad y significó la realización de varias obras arquitectónicas destacadas de la expresión modernista en Rosario, convirtiéndose en las obras más importante de este autor fuera de España: la Casa de España (Entre Ríos y Santa Fe), el Club Español (Rioja entre Mitre y Sarmiento), el Palacio Cabanellas (Sarmiento y San Luís), el edificio Remonda Monserrat (Entre Ríos y San Lorenzo), el edificio de la confitería La Europea (San Luís 1145) y el edificio para el banco de España y Río de la Plata, hoy de Transatlántica (Rioja y Mitre).

En realidad suena extraño que un tipo de arquitectura que en su territorio de origen fuera parte de los grupos que propugnaban las localías y las autonomías (al extremo de ser los estandartes formales de grupos independentistas), fuera del 
territorio europeo, formara parte de aquello que representó al país entero. Hay en ello algo de complejo, emigraron, llegan al nuevo lugar y deben autodefinirse en una generalización que tiende más a la lectura del país de origen y no siempre del lugar de donde provienen.

Es claro que Francisco Roca i Simó, en su condición de insular (originario de las Islas Baleares) y a partir de haber llegado a la Argentina no por un proyecto migratorio de largo plazo, no podía ingresar en las generales de la ley respecto de otros inmigrantes. Este es un caso particular de un autor que llega con sus propias ideas y en alguna medida con la noción de "traer" al país las cosas más complejas y más recientes que se han elaborado en el viejo continente. Más allá de su relación con la población emigrada, esta idea de "traer" las nuevas ideas a modo de actualización intelectual y promoción de "lo moderno" fue la misma lógica de muchos de los arquitectos llegados a la Argentina desde la segunda mitad del siglo XIX hasta bien entrado el siglo XX. Sin duda, la situación "provinciana" del país en relación al resto de los países centrales (particularmente Europa y América del Norte) promovía tal estrategia en aquellos formados en esos territorios. Es necesario reconocer que además el país no tenía ningún tipo de producción intelectual que le permitiera establecer otras opciones para los profesionales que llegaron.

El valor de proponer una arquitectura "no academicista" o alejada de las ideas de la "École des Beaux Arts" es para Roca (como para la mayoría de los autores de aquella época) una cuestión que define su posición de mejorar la ciudad y los lugares, fueren cuales fueren. Aún, sin haber sido un ideólogo, es claro que su rol en tierras argentinas lo pondrá entre los pocos que ejercitaron una arquitectura que se aproximó a las ideas de la península Ibérica. Tal vez una de las mayores contribuciones sea justamente proponer con sus obras la discusión sobre el rol de la arquitectura como herramienta para el cambio en mejoría de la calidad de vida. Claramente el gran tema de la modernidad trasladado a la arquitectura. Proponer eso en el marco de un país que está construyéndose como tal y que utiliza parámetros diferidos en el tiempo en cinco décadas respecto de sus cronologías y lugares de origen, implica un rigor notorio respecto de sus propios ideales.

Debe decirse que no hay ninguna idea extrema ni absoluta en la arquitectura de Roca. Tampoco podemos decir que estos edificios construidos en Rosario fueran clara y genuinamente "modernistas", pero tampoco se apegan a la tradición de la academia, y en todo caso, lo que hacen es abrir una línea más, de las tantas ejercidas en las tierras de la cuenca del plata, que se definieron desde la hibridez y la mezcla de cualidades provenientes de diversas fuentes y orígenes.

\section{Un edificio para recibir inmigrantes}

En Actas de la Asociación Española con fecha 29 de agosto de 1910 se acepta el proyecto de "Renacimiento Español" presentado por el arquitecto Francisco Roca i Simo para la construcción de la nueva sede en el predio adquirido en la esquina de Entre Ríos y Santa Fe. Es una pena que los dibujos originales de Roca presentados a la Asociación y que constan en actas no han sido hallados. El día 
21 de enero de 1912 se coloca la piedra fundamental con una gran pompa organizada por los socios. Será en la sesión del 18 de diciembre de 1913 que se acuerda como fecha de inauguración del edificio el día 21 de enero de 1914, y lo raro es que no se realizó ningún festejo inaugural.

Más allá de la lógica experimental y de la búsqueda de una "nueva arquitectura" que diera origen a la idea de lo "no académico", la obra de Roca i Simó en el edificio de la Asociación Española plantea una clara continuidad con la referencia simbólica como método de proyecto. El edificio está plagado de citas formales que hacen referencia a temas valiosos para el autor o para el programa o para los dueños, o finalmente para la representación de los inmigrantes y de su país de origen frente a la sociedad local que los recibió.

Es interesante observar y analizar la fachada del edificio y el sentido de cada uno de sus detalles ornamentales. El mismo Roca en una carta dirigida entre 1912 y 1913 al Presidente de la Comisión Directiva de la Asociación, Sr. Enrique Rodríguez Llames, explica el porqué de sus decisiones y sus elecciones en este, como él lo llama, proyecto arquitectónico:

"Muy señor mío: correspondiendo a su amable invitación tengo sumo gusto en manifestarle cuales fueron las razones que pesaron en mi ánimo cuando, al serme encargado que trazara el proyecto de edificio para la Sociedad Española de Socorros Mutuos, tuve que plantearme la cuestión del orden arquitectónico a que debía vegetarse el futuro edificio. Asunto es este que tiene una gran importancia, puesto que el aspecto de un edificio ha de corresponder a su objeto, y que cada raza imprime a sus construcciones un sello particular que responde a su naturaleza y a su historia" (Carta de Roca a Rodríguez Llames: 1912)

Resulta complejo establecer una relación muy explícita con el código formal de los referentes más notables del Modernismo Catalán. Si bien el uso de referencias heráldicas podría ser una característica con esas arquitecturas, también es relativa a las lógicas de la Academia, y en la Asociación responde claramente a una idea de identificación con el país de origen. Merece la pena resaltar que la estrategia proyectual de la alusión aquí asume todo tipo de gesto relativo a los temas hispánicos, y la heráldica es tema protagónico, de ahí su posición fundamental e inevitablemente obvio de coronar la esquina del edificio. Es interesante indicar que no siempre la heráldica aparece en formato completo de "escudo". En este caso en particular imágenes zoomorfas (águilas y leones) participan de lugares protagónicos en la zona alta de la fachada, destacándose en el conjunto del ornamento, y son sin duda de origen heráldico y cumplen con el mismo tipo de función representativa de las tierras del origen de la comunidad.

Las unidades ornamentales que definen los vanos, están coronadas por encima de los dinteles y frisos con escudos, que nuevamente dan cuenta de su valor como elementos de comunicación. 
Este tipo de señales se completa con la presencia de la nomenclatura que a modo de cartelería comunica públicamente cuál es el nombre colectivo y representativo del edificio: "Casa de España". El nombre es genérico. No define pertenencia de sitio, pero tampoco hace alusión al programa (no aclara nada respecto de la existencia o no de departamentos o viviendas, y tampoco explica nada de su carácter institucional o qué tipo de instituciones aloja). A la vez, en las fachadas laterales los escudos vuelven a ser protagonistas de la distinción de sectores centrales como marco del complejo sistema de balcón y volumen saliente central que organiza esa parte de la obra en el sector intermedio de las plantas. El coronamiento del volumen de los balcones alineados verticalmente también se resuelve con un escudo de profusa ornamentación zoomorfa asociada al águila de dos cabezas.

En este sentido, es muy interesante que los elementos de representación del origen en un país como Argentina, en donde no hay monarquía y donde los atributos de Estado están representados por elementos como el escudo o la bandera, los escudos, y especialmente el de España, sean los elementos de mayor carga simbólica de lectura masiva. Los escudos, son la referencia directa del origen, pero también son la representación institucional de la colectividad en una sociedad que se estaba construyendo sumando colectividades muy diversas, incluso con desconocimiento de los idiomas de origen. Es ahí donde la comunicación visual utilizando escudos, garantiza la eficiencia para identificar un grupo por medio de un edificio.

En los interiores, tanto cielorrasos como sectores centrales de dinteles o arcos de vanos serán ornamentados con piezas de heráldica, en algunos casos resaltando la cuestión nacional española y en otros referenciándose a las regiones y provincias de la península.

La heráldica no es otra cosa que el intento de ligar a la condición real un edificio que no pertenece a la Corona, pero que en última instancia intenta representar desde la imagen la nación que lo rige.

"Como principal elemento decorativo del coronamiento de la obra he adoptado el llamado escudo imperial de Carlos V. que resume toda la grandeza de la época en que se inventó y que también encaja en san Gregorio y en San Pablo de Valladolid o en el monasterio del Parral de Segovia ...y que sobre todo despliega toda su magnificencia heráldica y decorativa de la puerta bisagra de Toledo, este es el que escogí como coronamiento de la tribuna de la calle de Entre Ríos, dejando para coronar la torre de la ochava que es la parte prominente del edificio, un escudo algo más modernizado guardado por los dos clásicos leones rematando así con el símbolo de España grande, nuestra casa de España de Rosario de Santa Fe..." (Carta de Roca a Rodríguez Llames: 1912)

Es evidente, tal como resulta del texto de la carta que escribiera Roca al presidente de la Comisión Directiva de la Asociación, que la capacidad representativa del origen e identidad españolas fueron de gran importancia para el proyecto así como también lo fue la idea de construir la imagen de la institución que alojaría. 
En este punto, Roca claramente cumplió en trabajar con valores y parámetros arquitectónicos acordes a su época y a las prácticas generalizadas entre los arquitectos contemporáneos. Es evidente que esta estrategia proyectual es continuista con toda la historia de la arquitectura de los códigos de proyecto clásico. No es el uso de los escudos una muestra de lógica modernista, sin embargo, para un inmigrante en un país no monárquico y con una "escasa" (según parámetros de la época) historia local, es claro que la cuestión cobra cierto rasgo de modernidad dieciochesca en tanto son objetos de representación de la nación del origen. Esa estrategia valora "una sola nación" y no la suma de viejos reinos medievales o incluso modernos. Es fundamental entender que esos viejos reinos (las actuales autonomías aproximadamente) están presentes en el trabajo de Roca. Están incluso con la misma estrategia del uso de los escudos. Pero está en una jerarquía menor, siendo esto muy claro con el uso del cabio de tamaño y posición de cada escudo, sea de representación nacional o regional interna en la península.

El proyecto implica un ejercicio crítico a la situación arquitectónica local. Sin duda para Roca, la presencia de arquitecturas no "hispánicas" y ligadas a otros orígenes o colectividades es objeto de desaprobación a punto de definirlas como causante de una ruptura en el desarrollo que se había logrado previamente. El predominio de estas otras arquitecturas le molesta, los edificios representan la manifestación de otros intereses culturales que no son los "hispanos".

“...yo como buen español, debía tener en cuenta que se trataba de la casa de una entidad española levantada en un país de origen español, de formación española, de carácter español y de tradiciones españolas. La tradición arquitectónica española, que había empezado a producir muy buenos frutos en la época colonial, fue rota violentamente el día en que se implantaron aquí los estilos italianos y franceses que hoy privan casi en absoluto. ¿Debemos los arquitectos españoles dar por muerta esta tradición...? No lo creo yo así, antes bien entiendo que debemos reaccionar con energía contra tales modas e ir a inspirar nuestras creaciones en las fuentes puras de nuestro arte antiguo..." (Carta de Roca a Rodríguez Llames: 1912)

Es interesante ver que para Roca, los territorios del Río de la Plata, aún lejanos de la península no le resultan "ajenos". Le resultan propios y especialmente los plantea como con un grado interesante de desarrollo arquitectónico en el período colonial. La lógica "nacional", del país de origen se vuelve central en un programa arquitectónico como un edificio para dar alojamiento temporal a quienes llegan directamente a estas tierras que, finalmente, le resultan desconocidas y que los esperan con la sorpresa de la presencia de otros recién llegados con diversas culturas. Para Roca, es obvio que estos territorios son aún (o deben ser) una extensión de los peninsulares. El edificio por tanto debe ser un fragmento de España en Argentina. 
No se encuentran indicadores de las búsquedas de elementos fuertemente novedosos, como suele suceder en los casos de las vanguardias europeas del final del siglo XIX. Aquí las columnas, semicolumnas y pilastras de los que Roca llama "tribunas" son (salvando algunos detalles) reconocibles como provenientes del mundo clásico. Sin embargo, las búsquedas residen en las formas de combinar (a veces originalmente, especialmente para el medio nacional argentino o simplemente para Rosario) partes ya existentes en otras arquitecturas. Habría que señalar, por ejemplo, la forma de relacionar los capiteles de la planta baja con el friso que define el borde superior de esta planta en la fachada. Podríamos señalar a su vez la presencia de "cartelas" en las esquinas superiores de los vanos de la planta baja. Las mismas adoptan las formas provenientes de volutas clásicas, ahora reutilizadas y resignificadas. Estas "cartelas" a modo de ménsulas paralelas a la fachada dan cuenta de cierta lógica de refuerzo del dintel, que si bien no es necesario (técnicamente), son una contribución a la complejidad visual y compositiva desde la abundancia de los detalles.

Las señales que Roca muestra, frente a la valoración del momento español del renacimiento son notorias. Es claro que ese período tiene un significado mayúsculo para el autor. Tal vez una de las cuestiones más complejas en Roca sea que esa vocación por la "arquitectura verdadera" absolutamente distinta del concepto de "moda" e intenta contrarrestarlo con una arquitectura ligada a un pasado "español". Es cierto que todas las vanguardias del siglo XIX plantearon la búsqueda de la "nueva arquitectura" en parte intentando llegar a una opción más verídica, más genuina, en definitiva mejor. Esa actitud da cuenta de cierta coincidencia con todos los momentos que desde el siglo XVIII en Europa y América se invocó la modernidad.

El trasfondo es siempre el mismo, la valoración extrema del carácter nacional de un estilo (el plateresco y los edificios referentes del mismo) que se liga a los tiempos de la unificación de las coronas en España. El tema es representar al país de origen por sobre todas las cosas. Representar a un país es claramente una cuestión de la modernidad por Revolución Francesa.

“...¿iHay que dudar ni un momento respecto del orden arquitectónico que se ha de seguir en un edificio levantado en América por españoles para que sirva de asiento a una Sociedad Española de Socorros Mutuos que desde el primer día ha sido llamada sin contradicción Casa de España? Evidentemente no, tal edificio no puede pertenecer a otro estilo sino a aquel tan rico y severo al mismo tiempo que se llama renacimiento español o plateresco y que significó el momento culminante de la grandeza de España, resueltamente opté por él..." (Carta de Roca a Rodríguez Llames: 1912).

La geometría de las fachadas, los componentes del diseño, la evidente utilización de partes como "ornamento adosado" a los paramentos, son algunos de los indicadores de esta actitud. 
La clara jerarquía superior dada a la esquina es visible a partir de los elementos colocados en ella. Es en este lugar del edificio en el que aparece el único elemento cilíndrico de toda la composición, y en él se localiza el único balcón (tribuna) que combina muro como parapeto y trabajo de herrería a modo de transparencia vanguardista del elemento de protección.

El ornamento concentrado en los vanos es una de las características más conocidas del "Renacimiento Español". Aquí es visible sistemáticamente en todos los vanos pero además establece una diferencia de calidad y cantidad de elementos de ornato según la jerarquía compositiva del vano y su lugar en el muro que lo contiene. Es necesario señalar que como ejemplo en la segunda planta en la fachada cada vano tiene como ornamento todos los elementos del sistema clásico, y cada vano los posee como piezas autónomas, que finalmente se repetirán sistemáticamente en todos los vanos de igual valía compositiva.

Mencionando partes del sistema expresivo clásico, resulta notorio el uso del apareamiento de pilastras o semicolumnas en puntos peculiares de las fachadas. Repitiendo una larga y vieja tradición que podemos rastrear incluso en los casos desarrollados por Andrea Palladio en el siglo XVI, esta estrategia refuerza los bordes o los puntos finales de las superficies de muro. También aquí Roca repite un procedimiento de proyecto que finalmente lo asocia a la cuestión tradicional y lo aleja de sus actitudes modernistas.

Las líneas verticales aparecen definidas con mucha claridad en todas las fachadas. Esta es otra actitud fácilmente relacionable con antecedentes del renacimiento italiano, y nuevamente pone en discusión la verdadera condición "hispánica" de los gestos y el total de la obra. Esas líneas verticales, se construyen exclusivamente con el ornamento y es su detalle lo que aumenta, en el caso de salientes o piezas como columnas y semicolumnas, su condición clásica. Nuevamente aquí aparece la cuestión de jerarquizar y diferenciar partes en el sistema compositivo del proyecto.

Al igual que en el Renacimiento Italiano (y muchas otras variantes del código clásico) las líneas horizontales de la fachada están materializadas por las cornisas, que a su vez dividen las plantas. Cada piso tiene una correspondencia en el exterior con la posición de una cornisa, permitiendo entonces entender en cierta medida el espacio interior, sin poder visualizarlo en forma directa. Es evidente que la espacialidad de cada local no se refleja de forma directa, como sucedería más adelante en el siglo XX en los edificios modernos. Sin embargo la lógica de superposición de locales por plantas, es decir la tradicional y muy antigua organización por apilamiento de porciones horizontales es absolutamente visible gracias a la presencia del ornamento y en especial las cornisas.

La horizontalidad también es marcada con una estrategia más sutil, pero tan tradicional como todas las decisiones proyectuales ya mencionadas. En cada planta, los elementos coincidentes en alineamientos verticales o en el tipo de parte, tienen algún grado de diferenciación respecto del inmediato superior o inferior. $\mathrm{Si}$ en una planta los balcones se definen en sus extremos laterales por semicolumnas, en el superior se definirán por columnas o en la planta inferior por pilastras. 
Cada vano organizado por plantas está asociado a unidades ornamentales y estilísticas diferentes. Esta ya repetida estrategia clásica permite establecer una cierta diferenciación de programa arquitectónico. Sin embargo, en esta obra no es fácil asociar estilos y programas según la lógica del modelo de palacio urbano renacentista florentino (programa en el cual se establece esta estrategia proyectual como modo de proceder específico frente a este tema).

Arcos y dinteles son resaltados y ornamentados profusamente, lo cual proporciona cierta tridimensionalidad a la fachada. Reiteradamente en este punto Roca cumple con las prácticas establecidas y asienta la originalidad del caso en el tipo de combinación o el tamaño de los elementos que sobresalen del filo de los paramentos. Las tribunas a las que Roca destina una descripción particular en su texto, también favorecen a cierta presencia de tridimensionalidad en la fachada.

En los sectores altos de la fachada existe una profusa cantidad y calidad de pináculos y crestería, que como todos los elementos de la composición están referidos a otras obras de arquitectura y que el mismo Roca define con precisión el tipo e intensidad de esa relación.

“...orné las columnas y pilastras con detalles que recuerdan la fachada de la Universidad de Oñate y la desaparecida casa Gralla de Barcelona y el palacio Monterrey de Salamanca. Los bajos recuerdan los pórticos de los palacios municipales de nuestras viejas ciudades como el de Salamanca. El guarda polvo de los balcones principales está inspirado en los de las casas consistoriales de Sevilla. La galería de la calle de Entre Ríos recuerda los ventanales de la casa de las Conchas de Salamanca. La galería alta o ático es por el estilo de la casa de los Guzmanes de León, del palacio ya nombrado de Monterrey o el palacio de los Condes de Gomara de Soria ...el modelo de la torre de la ochava se halla a si mismo en las casas consistoriales de Alicante, en el Ayuntamiento de León, y aquí y allí hay detalles inspirados en el arco de San Gil de Burgos, en el Alcázar de Toledo, en el patio de las escuelas menores de Salamanca, en San Marcos de León, en el entresuelo del palacio arzobispal de Alcalá de Henares, en el pulpito grande de la catedral de Palma de Mallorca, otro recuerdo de la Baleares son las mayólicas que decoran el ático..." (Carta de Roca a Rodríguez Llames: 1912)

Los balcones sobre la calle Entre Ríos, alineados en posición vertical y sobresaliendo del paramento principal conforman un sistema complejo de gran presencia en el conjunto. En este segmento es remarcable la repetición de la estrategia de definir los bordes laterales con pilares, pilastras apareadas y finalmente con columnas apareadas en la última planta. A su vez, y retomando las prácticas del siglo XV italiano, en cada planta hay una explícita diferenciación jerárquica y programática que se apoya en los valores formales de los elementos del ornamento.

Si bien cierta lógica repetitiva aparece en estos diseños, los balcones son particularmente piezas que presentan fuerte diversidad de casos y actitudes. En 
todo el edificio existen varios modelos muy diferentes entre sí. Esta diferenciación se sostiene en las variaciones del uso de la herrería y su combinación con la mampostería (balcón francés, balcón con pretiles en voladizo, balcón con herrería con mampostería).

Los colores en la fachada se concentran en la última planta. Su materialidad está exclusivamente dedicada al uso del revestimiento de mayólicas y coincide con la regularidad de los vanos con arcos de medio punto como dintel. Se alternan con vanos con carpintería y utilizan como motivo casos de la heráldica española (como ya detalláramos anteriormente).

Existe una gran diferencia entre el tipo y densidad de la definición del exterior respecto de los espacios interiores. Cabe recordar que el edificio tuvo un programa complejo que implicó la existencia de oficinas y atención al público así como viviendas multifamiliares. En ese sentido es dable plantear que los interiores mayoritariamente no tuvieron el mismo tipo de valoración en lo que hace a la construcción de la imagen institucional de la "Casa de España". Excepto por algunos locales de uso comunitario o institucional, el tipo y densidad ornamental de la fachada no se repite en los interiores.

No es una característica exclusiva de Roca el proyectar valorizando fuertemente el exterior. Para la mayoría de estos autores finiseculares, el exterior de un edificio era el punto de mayor capacidad representativa, en todo caso da cuenta de la importancia de la imagen pública de la arquitectura hacia fines del siglo XIX y principios del XX. Esta característica pone nuevamente a Roca a cierta distancia de los casos más dogmáticos de la arquitectura del Modernismo o las Vanguardias del siglo XIX.

La Casa de España es un claro ejemplo de la forma de proyectar en los tiempos que hemos descrito. La estrategia de hacer referencias o aludir explícitamente a otros edificios al extremo de reconocerlos como fuente de proyecto fue, durante muchos siglos, el formato más utilizado por todos los autores. Esta fue la característica más determinante para que el código clásico en arquitectura sobreviviera tanto tiempo. Su vigencia se extendió desde la antigüedad Clásica (Grecia y Roma), pasando por el Renacimiento Italiano (siglos XV y XVI) y llegando al siglo XX y a nuestras tierras de la cuenca del Plata.

\section{Marcas urbanas y patrimonio}

La preservación de los vínculos de los inmigrantes de las diferentes regiones de España con su tierra de origen refuerza la idea de que la emigración no necesariamente implicaba una fractura de la cual solo cabía esperar consecuencias dolorosas. Por el contrario incluía nuevas líneas de relación y variables según el grado de integración de los emigrantes en los países de destino y las formas de redefinición de sus propias identidades colectivas. Es posible plantear que aún con la nostalgia y desarraigo, para muchos también se accedió una vida diferente que en muchos casos incluyó una mejora cualitativa. Eso incluyó una forma de comprender la cultura original distinta a la que tenían en sus lugares. De por sí, el con- 
cepto de Nación en un sentido cultural (no sólo político o geopolítico) como un conjunto de componentes fuertemente asociados fue algo más claramente comprendido en las nuevas tierras que en las del nacimiento.

Sin duda en el paisaje urbano quedaron las marcas, como expresión y testimonio de la interacción y de la diversidad cultural. La impronta de la inmigración en general y de la inmigración española en particular formó parte en el proceso de transformación que tienen todas las ciudades. Estas huellas, a modo de testimonios, convierten a la arquitectura y a la ciudad en un documento histórico de valor patrimonial para comprender los modos de vida y las expresiones de los hombres a través del tiempo. Testimonios, que sin ninguna duda, debemos preservar como expresión de una identidad para los rosarinos.

El paisaje urbano de Rosario y de muchas otras ciudades del país tiene como rasgo identitario la diversidad. La heterogeneidad que caracteriza a las ciudades de esta región del Plata, resultó nítidamente de las contribuciones múltiples y diversas de la enorme cantidad de situaciones distintas que desarrollaron estos pobladores venidos de muchos lugares del mundo. El caso especial de Roca, permite ver una situación muy especial, la de un "no migrante" que trabajó intensa, breve y especialmente para los emigrados y que desde una posición claramente de elite (cultural y económica) entendió que su rol debía dar cuenta del reforzamiento de la relación con el origen, en territorios que según él, nunca habían dejado de ser parte del conjunto delos tiempos coloniales. Esa situación, imposible de leer en la Península, pero también muy difícil de encontrar en otros territorios antiguamente pertenecientes a España, es claramente una de las características que definen nuestro patrimonio, son las marcas urbanas que juntos con muchos otros elementos, permiten explicar quiénes somos, y por lo tanto deben ser preservados.

\section{Bibliografía}

AAVV. 2006. Ecos del modernismo catalán en el Río de la Plata. Documento de Trabajo 151. Universidad de Belgrano. Director F. Martínez Nespral. Universidad de Belgrano. Buenos Aires. Argentina.

AAVV. 2006. Españoles en la arquitectura rioplatense: siglos XIX y XX. Coordinado por Patricia Méndez. CEDODAL. Buenos Aires. Argentina.

AAVV. 1998. Arquitectura Latinoamericana en el siglo XX. Coordinador Ramón Gutiérrez. Lunwerg Editores. Barcelona. España.

Valentini, M. Marull, M.V. y J. García Cano. 2007. "El arquitecto Francisco Roca y su obra en la ciudad de Rosario. El edificio "Casa de España". Presentado para ser publicado en el libro "Los Españoles en sociedad. Inmigración, territorio y trama asociativa en Rosario". ISBN: 978-987-05-3003-9.

Recibido: 14 de junio de 2016.

Aceptado: 25 de junio de 2016. 